\title{
Efficacy of intraarticular steroid injection in knee osteoarthritis using knee society score and visual analog score
}

\author{
Shriram Sampath, J. K. Giriraj Harshavardhan*
}

\begin{abstract}
Department of Orthopaedics Surgery, Sri Ramachandra Medical College and Research Institute, Chennai, Tamil Nadu,
\end{abstract} India

Received: 18 October 2018

Revised: 14 December 2018

Accepted: 18 December 2018

\section{*Correspondence:}

Dr. J. K. Giriraj Harshavardhan,

E-mail: girirajh@yahoo.com

Copyright: () the author(s), publisher and licensee Medip Academy. This is an open-access article distributed under the terms of the Creative Commons Attribution Non-Commercial License, which permits unrestricted non-commercial use, distribution, and reproduction in any medium, provided the original work is properly cited.

\section{ABSTRACT}

Background: Osteoarthritis of knee is a chronic degenerative joint disease which leads to pain, swelling, stiffness and decreased quality of life. The purpose of this study was to assess the effect of intra-articular steroid injection for osteoarthritis knee by using knee society score (KSS) and visual analog scale (VAS).

Methods: A prospective study of 38 patients ( 44 knees) diagnosed with osteoarthritis of knee were given $80 \mathrm{mg}$ of intra-articular methylprednisolone injection. The outcome was assessed using KSS and VAS before the injection and 3 months post injection.

Results: The mean VAS improved 3 months post injection whereas there was no improvement in the mean KSS. The scores of VAS 3 months post injection were statistically significant whereas the KSS scores were statistically insignificant compared with the pre injection values.

Conclusions: Intra-articular steroid injection for osteoarthritis of knee produces significant pain relief for most patients even in severe cases but this not translate to better functional outcomes.

Keywords: Osteoarthritis, Methylprednisolone acetate injection, Knee society score, Visual analog score

\section{INTRODUCTION}

Osteoarthritis of knee is a progressive chronic degenerative disease characterized by varying degrees of joint cartilage loss with local inflammation usually affecting the elder population. The disease processes involves the entire joint, including the articular cartilage, subchondral bone, ligaments, capsule, synovial membrane and periarticular muscles. ${ }^{1}$ The exact mechanism causing pain in Osteoarthritis knee is not well understood, probably a complex and multifactorial pathophysiology involving structural, psychosocial and neurophysiology factors. ${ }^{2}$
Patients presents with pain, swelling, stiffness and deformity of the joint thereby affecting their daily activities. ${ }^{3}$ Non operative measures of treatment include weight loss, physical therapy, oral analgesics, NSAID's, Interferential therapy and intra-articular injections.

Operative measures include high tibial osteotomy or total knee arthroplasty. Intra-articular injections are common non operative treatment used in patients resistant to oral analgesics and physiotherapy even in severe cases who are not willing for surgery. Intra-articular steroid injections are used widely for the treatment of osteoarthritis non-operatively. 
The purpose of this study was to evaluate the effect of intra-articular steroid injection based on VAS and KSS pre-injection and 3 months post-injection for osteoarthritis of knee.

\section{METHODS}

This prospective study was conducted in Sri Ramachandra Institute for Higher Education and Research (deemed to be university), Chennai from June 2016 to November 2016.

Ethics Approval was obtained from Ethics committee in Sri Ramachandra Institute for Higher Education and Research (deemed to be university).

\section{Inclusion criteria}

Patients with primary osteoarthritis of knee. Kellgren Lawrence grades 2 to 4 who were symptomatic were included in the study. Even very severe cases of osteoarthritis knee who were not willing for surgery were included.

\section{Exclusion criteria}

Secondary osteoarthritis and past history of Intra-articular injection were excluded.

\section{Procedure}

All the patients were given Injection Methylprednisolone $80 \mathrm{mg}(2 \mathrm{ml})$ without local anesthesia into lateral tibiofemoral compartment with knee flexed. In our study we evaluated the patients before administration of injection with routine blood investigations, any abnormal values such as sugars, thyroid function were corrected before injection.

\section{Follow up}

The effect was assessed using KSS (as per Insall modification, 1993) and VAS scores, pre injection and 3 months post injection and the results were compared.

Patients were contacted over telephone if they were not coming for follow up. No patients were lost for follow up at the end of 3 months. At presentation we assessed for pain using VAS and we assessed for any improvement in functional outcome using KSS.

\section{Knee society score}

At the initial stage before injection all the patients had a mean KSS of 72 with a range of 54 to 82 . At 3 months post injection their KSS were 73 (Table 2). This showed that there was no improvement in KSS pre and post steroid injection. The $\mathrm{p}$ value was found to be $>0.05$ which was statistically not significant.
Table 1: Knee society score. ${ }^{4}$

\begin{tabular}{|c|c|}
\hline Parameters & Points \\
\hline \multicolumn{2}{|l|}{ Pain-walking } \\
\hline None & 35 \\
\hline Mild or occasional & 30 \\
\hline Moderate & 15 \\
\hline Severe & 0 \\
\hline \multicolumn{2}{|l|}{ Pain-stairs } \\
\hline None & 15 \\
\hline Mild or occasional & 10 \\
\hline Moderate & 5 \\
\hline Severe & 0 \\
\hline \multicolumn{2}{|l|}{ Range of motion } \\
\hline 5 degrees $=1$ point & $\begin{array}{l}0 \text { to } 5 \text { degrees }-1 \text { point } \\
121 \text { to } 125 \text { degrees and more } \\
-25 \text { points (maximum) }\end{array}$ \\
\hline \multicolumn{2}{|c|}{ Stability- medial/lateral } \\
\hline $0-5 \mathrm{~mm}$ & 15 \\
\hline $5-10 \mathrm{~mm}$ & 10 \\
\hline$>10 \mathrm{~mm}$ & 5 \\
\hline \multicolumn{2}{|c|}{ Stability-anterior/posterior } \\
\hline $0-5 \mathrm{~mm}$ & 10 \\
\hline $5-10 \mathrm{~mm}$ & 8 \\
\hline$>10 \mathrm{~mm}$ & 5 \\
\hline \multicolumn{2}{|c|}{ Deductions- extension lag } \\
\hline None & -0 \\
\hline$<4$ degrees & -2 \\
\hline 5-10 degrees & -5 \\
\hline$>11$ degrees & -10 \\
\hline \multicolumn{2}{|l|}{ Flexion contracture } \\
\hline$<5$ degrees & -0 \\
\hline 6 to 10 degrees & -3 \\
\hline 11 to 20 degrees & -5 \\
\hline$>20$ degrees & -10 \\
\hline \multicolumn{2}{|l|}{ Malalignment } \\
\hline $\begin{array}{l}5 \text { to } 10 \text { degrees valgus } \\
\text { (normal) }\end{array}$ & -0 \\
\hline $\begin{array}{l}\text { For every } 5 \text { degrees } \\
\text { deviation from normal }\end{array}$ & -2 \\
\hline \multicolumn{2}{|l|}{ Pain at rest } \\
\hline Mild & -5 \\
\hline Moderate & -10 \\
\hline Severe & -15 \\
\hline
\end{tabular}

\section{Visual analog score}

At the initial stage before injection all the patients had a mean VAS of 7.2 with a range of 5 to 9 . At 3 months post injection their VAS was 4.3 (Table 2). This showed that their VAS score improved considerably pre and post steroid injection. The $\mathrm{p}$ value was found to be $<0.05$ which was statistically significant. 
The concept of standard error of difference between two means (pre op and post injection VAS and KSS) was used to determine the statistical significance of the data by applying the chi-square test.

\section{RESULTS}

\section{Demographic data}

Thirty eight patients ( 44 knees) between 58 to 84 years of age with a mean age of 67 years were part of the study (Figure 1) 6 patients had bilateral OA knee, 22 males and 16 females.

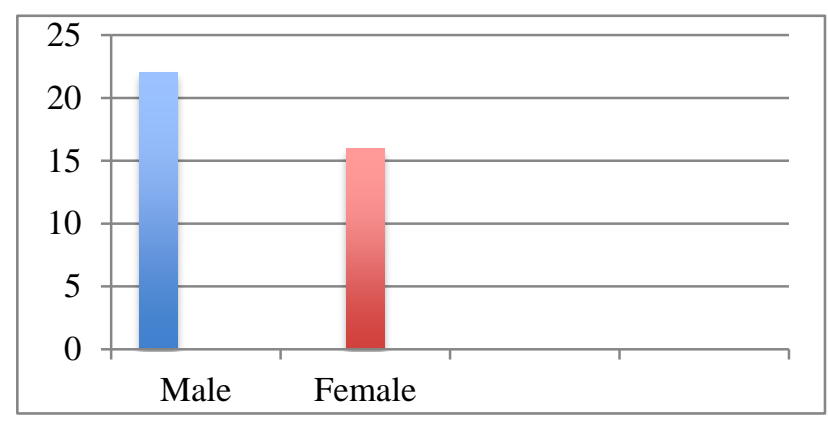

Figure 1: Demographic data.

The VAS, 3 months after injection showed significant improvement as compared to KSS, 3 months after injection.

Thus in our study, the $\mathrm{p}$ value for knee society score preinjection and post-injection was found to be $>0.05$ which was statistically not significant and the $\mathrm{p}$ value for visual analog score pre-injection and post-injection was found to be $<0.05$ which was statistically significant (Table 2).

Table 2: Scoring.

\begin{tabular}{|llll|}
\hline & Pre injection & $\begin{array}{l}\text { Post injection } \\
\text { (3 months) }\end{array}$ & P value \\
\hline $\begin{array}{l}\text { Visual } \\
\text { analog } \\
\text { score }\end{array}$ & 7.2 & 4.3 & $<0.05$ \\
\hline $\begin{array}{l}\text { Knee } \\
\text { society } \\
\text { score }\end{array}$ & 72 & 73 & $>0.05$ \\
\hline
\end{tabular}

Thus intra-articular steroid injection for osteoarthritis of knee helps relieve pain in those who are not responding to conservative management for a brief period of time but it does not translate to better functional outcomes.

\section{DISCUSSION}

Corticosteroids are anti-inflammatory and immunesuppressive agents acting directly on nuclear receptors and interrupting the inflammatory and immune cascade., They reduce vascular permeability and inhibit the synthesis and secretion of several inflammatory mediators by inhibiting cycloxygenase and lipoxygenase pathways.

Although $\mathrm{OA}$ is primarily a degenerative disorder, there is evidence of the presence of inflammatory mediators whose effects are attenuated by the use of corticosteroids. The use of intraarticular corticosteroids has immediate analgesic effects however long term outcomes show no great improvement in functional outcomes. ${ }^{7,8}$ This is believed to be due to the fact that the period of analgesia permits increased mobility and therefore causes increase articular cartilage damage due to weight bearing on an unhealthy knee joint. ${ }^{9}$

In our study we used Injection Methylprednisolone (80 $\mathrm{mg}) 2 \mathrm{ml}$ for injection into the lateral tibiofemoral compartment without local anesthesia. Cooper et al in his study published in 2017 used intra-articular Hyaluronic acid for osteoarthritis of knee and showed good results. ${ }^{3}$ In a comparative study between Methylprednisolone and Hyaluronic acid for osteoarthritis knee Leighton et al in his study published in 2014 concluded that the effect of Methylprednisolone and Hyaluronic acid were same upto 12 weeks but at 26 weeks the effect of hyaluronic acid was maintained but the effect of methylprednisolone declined. $^{5}$

Wernecke et al in his study published in 2015 did a systematic review using 1929 articles and he stated that maximum dose of methylprednisolone acetate injected should be not more than $30 \mathrm{mg}$, higher doses of injection causes damage to articular cartilage. ${ }^{9}$ In our study we injected $80 \mathrm{mg}$ of methylprednisolone acetate, At this dose if it really causes damage to articular cartilage was not assessed in this study but we found good improvement with respect to pain with this dose.

Our study did not assess mid-term or long term outcomes of intra-articular steroid injections whereas Raynauld et al in his study published in 2003 assessed the safety and efficacy of long term intra-articular steroid injections (2 years) for knee pain related to osteoarthritis and concluded that repetitive IA steroid injections appear to be safe, also he concluded that long term use of IA injections afforded pain relief. ${ }^{8}$

In a study published by Beyaz et al in 2012 he assessed the efficacy of intra-articular morphine and steroid in patients with osteoarthritis and concluded that intraarticular morphine was as effective as intra-articular steroid for analgesia in patients with osteoarthritis knee and intra-articular morphine is possibly a better option than intra-articular steroid as it has lesser side effects. ${ }^{10}$

Intra-articular steroid injection will continue to play a significant role in the management of osteoarthroses knee in our country as many patients are hesitant to undergo a total knee replacement even in severe cases in view of the possible complications and costs involved. Our 
population is willing to alter their lifestyle to accommodate the pain rather than undergoing a major surgical procedure. ${ }^{11}$

Our study is unique in the sense we have used KSS whilst most studies use the WOMAC scoring system to assess the functional outcome. ${ }^{10}$

\section{CONCLUSION}

Intra-articular steroid injection for osteoarthritis of knee produces significant pain relief for most patients even in severe cases but this does not translate to better functional outcomes.

Funding: No funding sources Conflict of interest: None declared

Ethical approval: The study was approved by the institutional ethics committee

\section{REFERENCES}

1. Bellamy N, Campbell J, Robinson V, Gee T, Bourne R, Wells G. Intraarticular corticosteroid for treatment of osteoarthritis of the knee. Cochrane Database Syst Rev. 2006;(2):CD005328.

2. Lluch E, Nijs J, Courtney C, Rebbeck T, Wylde V, Baert I, et al. Clinical descriptors for the recognition of central sensitization pain in patients with knee osteoarthritis. Disabil Rehabil. 2018;40(23):283645.

3. Cooper C, Rannou F, Richette P, Bruyere O, AlDaghri N, Altman RD, Brandi ML, et al. Use of intraarticular hyaluronic acid in the management of knee osteoarthritis in clinical practice. Arthritis Care Res. 2017;69:1287-96.

4. Insall JN, Dorr LD, Scott RD, Scott WN. Rationale of the Knee Society clinical rating system. Clin Orthop Relat Res. 1989;248:13-4.

5. Leighton R, Åkermark C, Therrien R, Richardson J, Andersson M, Todman M, et al. NASHA hyaluronic acid vs methylprednisolone for knee osteoarthritis: a prospective, multi-centre, randomized, noninferiority trial. Osteoarthritis and Cartilage. 2014;22(1):17-25.

6. Dutta D, Ghosh S, Mukhopadhyay P, Mukhopadhyay S, Chowdhury S, Roy A. Efficacy and safety of low dose oral prednisolone as compared to pulse intravenous methylprednisolone in managing moderate severe Graves' orbitopathy: A randomized controlled trial. Indian $\mathbf{J}$ Endocrinol Metab. 2015;19(3):351.

7. McCrum C. Therapeutic Review of Methylprednisolone Acetate Intra-Articular Injection in the Management of Osteoarthritis of the Knee - Part 1: Clinical Effectiveness. Musculoskeletal Care. 2016;15(1):79-88.

8. Raynauld J, Buckland-Wright C, Ward R, Choquette D, Haraoui B, Martel-Pelletier J, et al. Safety and efficacy of long-term intraarticular steroid injections in osteoarthritis of the knee: A randomized, double-blind, placebo-controlled trial. Arthritis Rheum. 2003;48(2):370-7.

9. Wernecke C, Braun HJ, Dragoo JL. The effect of intra-articular corticosteroids on articular cartilage. Orthop J Sports Med. 2015;27:2325967115581163.

10. Beyaz S. Comparison of efficacy of intra-articular morphine and steroid in patients with knee osteoarthritis. J Anaesthesiol Clin Pharmacol. 2012;28(4):496.

11. Henriksen M, Christensen R, Klokker L, Bartholdy C, Bandak E, Ellegaard K, et al. Evaluation of the Benefit of Corticosteroid Injection Before Exercise Therapy in Patients With Osteoarthritis of the Knee. JAMA Intern Med. 2015;175(6):923-30.

Cite this article as: Sampath S, Harshavardhan GJK. Efficacy of intraarticular steroid injection in knee osteoarthritis using knee society score and visual analog score. Int J Res Orthop 2019;5:299-302. 